\title{
Cross-regional cold chain fresh product logistics network based on GO-FLOW analysis
}

\author{
Xuan Ma and Huisheng Gao* \\ Department of Express and Logistics, Shijiazhuang Posts and Telecommunications Technical College, Shijiazhuang 050021, \\ PR China
}

Received: 11 June 2020 / Accepted: 11 September 2020

\begin{abstract}
Fresh products have a large loss in the process of cross-regional logistics. In this study, the crossregional fresh cold chain logistics network was analyzed using GO-FLOW analysis method. First, the basic principle of GO-FLOW analysis method was introduced. Then, taking the cold chain logistics network of mangosteen as an example, the GO-FLOW diagram was established, the signal strength was calculated, and the logistics network was improved according to the analysis results. The results showed that the reliability of the logistics network was 0.842 , among which the reliability loss in precooling, long-distance transportation and sales was the largest. After improving the logistics network according to the three links, the reliability of the logistics network rose to 0.958 , increased by $5.53 \%$, among which the long-distance transportation link increased by $9.03 \%$. The analysis results verifies the feasibility of GO-FLOW analysis method in logistics network analysis and make some contributions to improve the efficiency of physical network and ensure food safety.
\end{abstract}

Keywords: Cold chain logistics / GO-FLOW method / logistics network analysis / mangosteen / long-distance transportation

\section{Introduction}

When fresh products are preserved at room temperature, their nutritional value will be greatly reduced, and they are also prone to deterioration, which will not only affect their sales value, but also damage the health of consumers after market circulation. In order to effectively extend the shelf life of fresh products and prevent food deterioration, cold storage technology can be used in the process of storage and transportation, i.e. cold-chain logistics mode [1]. With the development of economy, the demand of people for cold chain fresh products is also increasing [2]. At present, crossregional fresh cold chain logistics includes frozen food, meat products, fruits and vegetables, etc. However, the cold chain logistics of China is still in its infancy, there are still many problems [3], and the loss rate of fresh products in the logistics link is also high [4]. Therefore, the safety and reliability of fresh products in the process of logistics network circulation have been widely concerned by researchers. Zhang et al. [5] studied the quality changes of fresh cut parsley at different positions in the refrigerator car and found that the shelf life of parsley at the upper part of the refrigerator car was 6 days and the shelf life of parsley

\footnotetext{
* Corresponding author: hs12x1@163.com
}

at the lower part was 8 days, which was caused by the different vibration intensity at different positions in the car. Zhang et al. [6] established the risk assessment model of cold chain logistics of agricultural products by combining the catastrophe progression method with the maximum variance method, conducted experiments in two representative enterprises, and found that the model was in good agreement with the actual situation and could scientifically reflect the key risks in the logistics network. Zhao et al. [7] found that the use of computational fluid dynamics in the analysis of agricultural cold chain logistics was of great significance to improve the temperature uniformity, reasonably control the refrigeration time and improve the value of cold chain and analyzed its future development trend. Lv et al. [8] analyzed the quality of litchi under different packaging methods and pointed out that the use of sealed bags and packaging with air holes could significantly reduce litchi browning and reduce the rate of quality loss. In this study, the cross-regional fresh cold chain logistics network was analyzed using GO-FLOW analysis method, and the main factors affecting the reliability of the logistics network were found out and improved by performed detailed study on mangosteen. The analysis results showed that it was feasible to use GOFLOW method to analyze the logistics network, which is conducive to understanding the reliability of each link in 

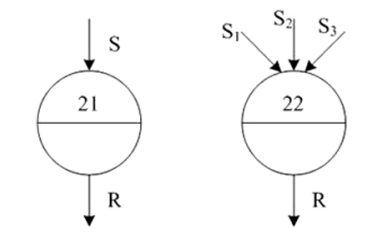

Two-state element OR gate
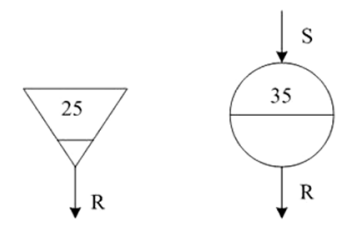

Signal generator Working element that fails over time

Fig. 1. GO-FLOW modeling operators.

the logistics network and thus making reasonable adjustment to realize the logistics network to the maximum extent.

\section{GO-FLOW analysis of cross regional cold chain fresh product logistics network}

\subsection{GO-FLOW analysis method}

GO-FLOW analysis method can express complex problems through a simple model and get system risks through simple calculation. The model is simple [9] and easy to change, which has been widely used in system security analysis [10]. It mainly includes 14 standard operators, and 3 of them are used in this study, as shown in Figure 1.

In Figure 1, $S$ represents the main input signal, $R$ represents the output signal, the connecting line between operators is the signal line, and GO-FLOW analysis is conducted from top to bottom along the signal line. In the analysis of the GO-FLOW diagram, the operator needs to be determined at first, then the operators are connected by signal lines, and finally the whole GO-FLOW diagram can be obtained. In the GO-FLOW diagram, the most important thing is operators and their relationship. A correct GO-FLOW diagram needs to meeting the following conditions : 1) the operator number is unique; 2) there is at least one signal generator; 3 ) the signal flow sequence is not recyclable; 4) all signal flows must have unique numbers; 5) the termination signal is clearly defined.

\subsection{Cold chain logistics of mangosteen}

Garcinia mangostana L., originated in Malaysia, is mainly distributed in the Philippines, Thailand, Myanmar, etc. In China, it is mainly distributed in coastal areas such as Taiwan, Fujian and Guangdong. It is a famous tropical fruit, rich in protein and lipids, and has a good nourishing effect on the body [11]; hence it is widely loved by people. The circulation of mangosteen outside the production area must go through steps of storage and transportation. However, after picking, mangosteen is easy to have lignification, browning, rot, etc, which will seriously affect the quality and value of mangosteen. In order to reduce the rot, it is necessary to adopt the method of low temperature treatment to inhibit the rot of mangosteen by means of cold chain logistics. The cold chain logistics network of mangosteen is shown in Figure 2.

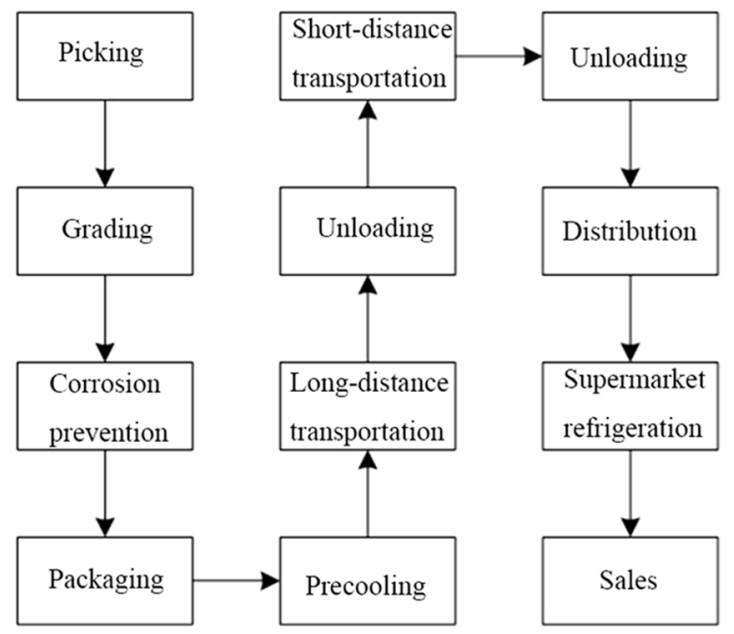

Fig. 2. The cross-regional mangosteen cold chain logistics network.

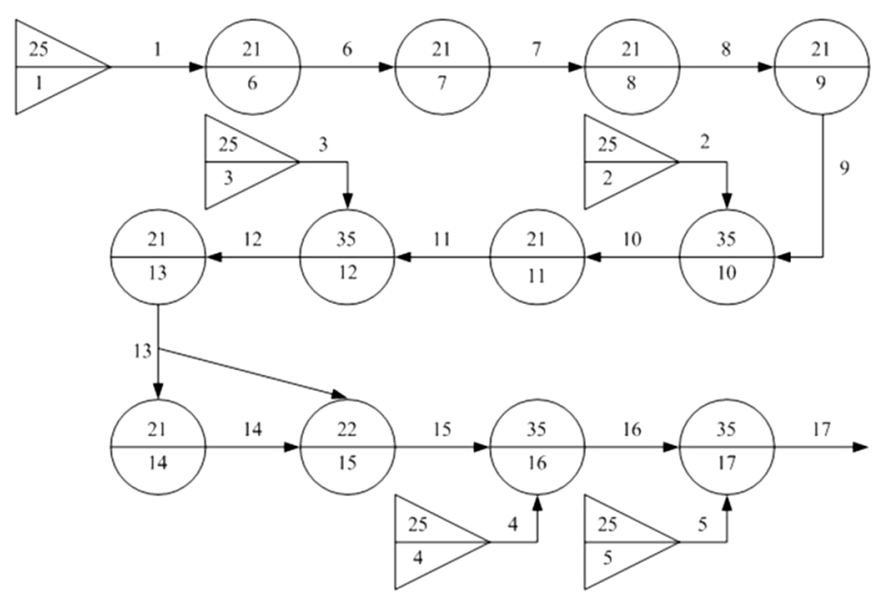

Fig. 3. The GO-FLOW diagram of the cross-regional mangosteen cold chain logistics network.

\subsection{Establishment of GO-FLOW diagram}

According to the cold chain logistics network of mangosteen, a GO-FLOW diagram is established. It is assumed that there is only one mangosteen picking place, which is represented by type 25 in Figure 1 . The classification, anticorrosion, packaging, precooling, unloading and distribution have states of successful and faulty, which are all represented by type 21 ; the freshness of mangosteen in other stages will decrease with time, which is represented by type 35 . The established GO-FLOW diagram is shown in Figure 3.

\subsection{Type number operation rules}

At time point $t$, the security of mangosteen is represented by signal intensity; the higher the signal intensity is, the higher the safety of mangosteen is. The initial security of mangosteen is the main input signal intensity, which is set as $S(t)$. The final security of mangosteen is the output 
Table 1. Operator data.

\begin{tabular}{llll}
\hline Number & Type & Parameter & Designation \\
\hline 1 & 25 & 1 & Pick \\
2 & 25 & $3 \mathrm{~d}$ & Long distance transportation time \\
3 & 25 & $0.5 \mathrm{~h}$ & Short distance transportation time \\
4 & 25 & $4 \mathrm{~d}$ & Supermarket cold storage time \\
5 & 25 & $4 \mathrm{~d}$ & Sales time \\
6 & 21 & 0.98 & Classification \\
7 & 21 & 0.97 & Anticorrosive \\
8 & 21 & 0.98 & Packing \\
9 & 21 & 0.95 & Pre-cooling \\
10 & 35 & $0.02 / \mathrm{d}$ & Long-distance transport \\
11 & 21 & 0.97 & Unload \\
12 & 35 & $0.001 / \mathrm{d}$ & Short distance transportation \\
13 & 21 & 0.97 & Unload \\
14 & 21 & 0.96 & Delivery \\
15 & 22 & None & Or gate \\
16 & 35 & $0.001 / \mathrm{d}$ & Supermarket refrigeration \\
17 & 35 & $0.03 / \mathrm{d}$ & Sale \\
\hline
\end{tabular}

signal intensity, which is set as $R(t)$. The number of time points is $n$. The operation rules of the operators used in Figure 3 refer to the study of Fan et al. [12]:

- type 21: $R(t)=S(t) \cdot P$, where $P$ refers to the success probability of the component;

- type 22: $R(t)=1-\prod_{i=1}^{n}\left(1-S_{i}(t)\right)$;

- type 25: the reliability of the output signal is the operator reliability;

- type 35: $R(t)=S(t) \exp \left\{-\delta \sum_{i} \sum_{k \leq t} P\left(t_{k}\right) \min \left[1, S\left(t_{k}\right) /\right.\right.$ $S(t)]\}$, where $\delta$ refers to the failure rate of components, i.e., the probability of security decline caused by decay, loss, etc. in the process of mangosteen transportation.

\section{GO-FLOW analysis results of cross-regional cold chain logistics network}

\subsection{GO-FLOW analysis of logistics network}

Through looking up materials and field research, the relevant operation time, failure rate and other data under the cold chain logistics of mangosteen were obtained. The parameter of type 25 represents the operator reliability, the parameter of type 21 represents component, i.e. the deterioration rate of mangosteen in this link, the parameter of type 35 represents component, i.e. the failure rate (deterioration rate) of mangosteen in unit time, as shown in Table 1.

The signal flow intensity is calculated according to the operation rules shown in Section 3.3, and the results are shown in Table 2.

It was seen from Table 2 that the reliability of the logistics network was low and the loss rate was large in links of precooling, long-distance transportation and sales; from packaging to precooling, the reliability of the logistics network decreased by $0.957-0.908=0.049$; after
Table 2. The signal strength of cross-regional mangosteen cold chain logistics network.

\begin{tabular}{lll}
\hline Number & Type & Output signal strength \\
\hline 1 & 25 & 1 \\
2 & 25 & $3 \mathrm{~d}$ \\
3 & 25 & $0.5 \mathrm{~h}$ \\
4 & 25 & $4 \mathrm{~d}$ \\
5 & 25 & $4 \mathrm{~d}$ \\
6 & 21 & 0.985 \\
7 & 21 & 0.975 \\
8 & 21 & 0.957 \\
9 & 21 & 0.908 \\
10 & 35 & 0.842 \\
11 & 21 & 0.839 \\
12 & 35 & 0.821 \\
13 & 21 & 0.818 \\
14 & 21 & 0.943 \\
15 & 22 & 0.941 \\
16 & 35 & 0.887 \\
17 & 35 & 0.832 \\
\hline
\end{tabular}

long-distance transportation, the reliability of the logistics network decreased by 0.066 ; in the sales link, the reliability of the logistics network decreased by 0.055 ; finally, the reliability of the logistics network was 0.832 , decreased by $16.8 \%$. The results of GO-FLOW analysis showed that it was necessary to reduce the time of long-distance transportation and sales and improve the reliability of precooling to improve the reliability of the mangosteen cold chain logistics network. 
Table 3. The signal strength of the improved logistics network.

\begin{tabular}{lll}
\hline Number & Type & Output signal strength \\
\hline 1 & 25 & 1 \\
2 & 25 & $2 \mathrm{~d}$ \\
3 & 25 & $0.5 \mathrm{~h}$ \\
4 & 25 & $4 \mathrm{~d}$ \\
5 & 25 & $2 \mathrm{~d}$ \\
6 & 21 & 0.985 \\
7 & 21 & 0.975 \\
8 & 21 & 0.957 \\
9 & 21 & 0.943 \\
10 & 35 & 0.936 \\
11 & 21 & 0.927 \\
12 & 35 & 0.916 \\
13 & 21 & 0.893 \\
14 & 21 & 0.957 \\
15 & 22 & 0.948 \\
16 & 35 & 0.976 \\
17 & 35 & 0.958 \\
\hline
\end{tabular}

\subsection{GO-FLOW analysis of the improved logistics network}

The logistics network was improved according to the results shown in Table 2 to improve the precooling reliability to 0.98 , shorten the long-distance transportation time to $2 \mathrm{~d}$, and shorten the sales time to $2 \mathrm{~d}$. The signal strength was recalculated, and the results are shown in Table 3 .

The output signal strength of the cross-regional mangosteen cold chain logistics network before and after the improvement was compared, and the results are shown in Table 4.

It was seen from Table 4 that the reliability of the improved logistics network increased from 0.832 to 0.958 , increased by $5.53 \%$, which showed that the security of the improved logistics network greatly improved and the loss of mangosteen significantly reduced. Among the long-distance transportation links, the improvement of the reliability was the most obvious, from 0.842 to 0.936 , with an increase of $9.03 \%$, which led to the improvement of the reliability of other links and ensured the reliability of the whole logistics network. It was found from the results of signal strength comparison that the improvement of precooling, long-distance transportation and sales was correct, which could effectively improve the reliability of the logistics network.

\section{Discussion}

Cold chain logistics has great development potential in fresh products, and its domestic demand is also increasing [13]. In order to effectively develop and
Table 4. Signal strength comparison of the logistics network.

\begin{tabular}{llll}
\hline Number & $\begin{array}{l}\text { Output signal } \\
\text { strength before } \\
\text { improvement }\end{array}$ & $\begin{array}{l}\text { Output signal } \\
\text { strength after } \\
\text { improvement }\end{array}$ & Increase \\
\hline 9 & 0.908 & 0.943 & $3.85 \%$ \\
10 & 0.842 & 0.936 & $9.03 \%$ \\
11 & 0.839 & 0.927 & $7.63 \%$ \\
12 & 0.821 & 0.916 & $7.92 \%$ \\
13 & 0.818 & 0.893 & $5.99 \%$ \\
14 & 0.943 & 0.957 & $1.48 \%$ \\
15 & 0.941 & 0.948 & $0.74 \%$ \\
16 & 0.887 & 0.976 & $5.07 \%$ \\
17 & 0.832 & 0.958 & $5.53 \%$ \\
\hline
\end{tabular}

optimize cold chain logistics, vehicle scheduling [14], path optimization [15], cold storage planning and construction and other issues of logistics network have been widely studied. In order to better understand the cross-regional cold chain fresh product logistics network, it was studied using GO-FLOW analysis method, and mangosteen was taken as an example. The result showed that the reliability of the mangosteen cold chain logistics network was 0.832 , and the links of precooling, longdistance transportation and sales caused great losses. Therefore, these three links were improved, and the signal strength of the improved logistics network was compared with that before the improvement. The result showed that the reliability of the improved logistics network increased by $5.53 \%$, and the reliability of the long-distance transportation link increased by $9.03 \%$, which showed that the improvement of the logistics network was reasonable. In order to improve the reliability of the logistics network of fresh and cold chain, the following things need to be done.

- Advanced refrigeration equipment such as refrigerators, refrigerators, etc. should be introduced.

- The precooling quality of the cold storage should be improved, the temperature and humidity information of the cold storage should be timely monitored, the cold storage should be checked before the new products are put into storage, and the deteriorated products should be timely cleared.

- The refrigerated door shall remain closed, and the product storage shall be completed in the shortest time, so as to reduce the entry of external temperature and humidity air.

- The latest science and technology should be made full use of to optimize the vehicle scheduling and distribution path, complete the transportation and unloading in the shortest time, and reduce the number of opening and closing the compartment door.

- The informatization operation of the cold chain logistics network [16] should be promoted to conduct real-time monitoring of each link [17] and achieve information sharing and management. 
- The temperature inside the transport vehicle must be suitable for the storage of products, which cannot be too high or too low.

- The temperature of the display cabinet shall be monitored at any time during sales, and the products in the display cabinet shall follow the principle of first-in first-out.

- The development of third-party cold chain logistics enterprises should be supported, and logistics outsourcing should be encouraged to improve logistics efficiency.

\section{Conclusion}

In this study, the cross-regional fresh and cold chain logistics network was analyzed using GO-FLOW analysis method. Taking mangosteen as an example, through the establishment of GO-FLOW diagram and the calculation and comparison of signal strength, it was found that:

- the reliability of the cross-regional cold chain logistics network was 0.842 ;

- precooling, long-distance transportation and sales have the greatest impact on the reliability of the logistics network;

- after the improvement, the reliability of logistics network increased by $5.53 \%$, among which the reliability of longdistance transportation increased by $9.03 \%$.

The analysis results verified the effectiveness of GOFLOW analysis method in logistics network analysis, which can be further promoted and applied in the analysis of security, risk and reliability of various physical networks.

\section{References}

1. X.C. Zhai, Y.F. Liu, Y. Wang, T. Ku, J. Food Safety Qual. 207-211 (2015)

2. W. Tao, Z. Wei, B. Li, J. Beijing Jiaotong Univ. 41, 28-33 (2017)

3. B. Chen, A. Zhou, Asian Agric. Res. 08, 19-21 (2016)

4. H. Sun, J. Liu, Z. Zhang, T.T. Jia, Q. Sun, LISS $633-638$ (2015)

5. C. Zhang, X.L. Dong, Y. Ma, X.Y. Zhao, Mod. Food Sci. Tech. 33, 176-180 and 299 (2017)

6. H. Zhang, B. Qiu, K. Zhang, Ind Manage. Data Syst. 117, 1800-1816 (2017)

7. C. Zhao, J. Han, X. Yang, J. Qian, S. Liu, Trans. Chin. Soc. Agric. Mach. 46, 214-222 (2015)

8. E.L. Lv, H.Z. Lu, S.X. Yang, J.H. Zhao, Q.L. Tian, Mod. Food Sci. Tech. 32, 156-160 and 93 (2016)

9. F. Zhao, L. Liang, S. Wang, Trans China Electrotech. Soc. 30, 351-356 (2015)

10. N. Mitomom, T. Okazaki, T. Aldemir, Transnav: Int. J. Marine Nav. Safety Sea. Transp. 8215, 3333-3338 (2016)

11. B. Krishnamachary, D. Subramaniam, T. Attard, S. Septer, S. Anant, Cancer Res. 77, 5175-5175 (2017)

12. D.M. Fan, Z.L. Wang, L.L. Liu, Y. Renv, Nucl. Eng. Des. 305, 476-488 (2016)

13. B. Ya, J. Comput. Theor. Nanos. 13, 4019-4024 (2016)

14. X. Ren, X. Zhu, Z. He, X. Xiang, D. Chen, J. Beijing Jiaotong Univ. 39, 125-132 (2015)

15. W. Yang, J. Zhao, K. Zhang, Y.N. Ou, Q. Li, Packaging Eng. 40, 72-79 (2019)

16. H. Luo, M. Zhu, S. Ye, H. Hou, Y. Chen, L.A. Bulysheva, Internet Res. 26, 435-445 (2016)

17. C. Chen, T. Chen, C. Zhang, G. Xie, IFIP Adv. Inform. Commun. Tech. 420, 247-254 (2015)

Cite this article as: Xuan Ma, Huisheng Gao, Cross-regional cold chain fresh product logistics network based on GO-FLOW analysis, Int. J. Metrol. Qual. Eng. 11, 7 (2020) 